\title{
Effects of a Two-Day Teachers' Training Course on Activity Time in Physical Education
}

\author{
Miriam Wanner'1, Eva Martin-Diener'1, Claudia Frick', ${ }^{1}$, Susi Kriemler ${ }^{3}$, Brian W. Martin' \\ ${ }^{1}$ Physical Activity and Health Work Unit, Institute of Social and Preventive Medicine, University of Zurich, Zurich, \\ Switzerland \\ ${ }^{2}$ Movement Sciences and Sports, Department of Health Sciences and Technology, Swiss Federal Institute of \\ Technology Zurich, Zurich, Switzerland \\ ${ }^{3}$ Institute of Social and Preventive Medicine, University of Zurich, Zurich, Switzerland \\ Email: miriam.wanner@uzh.ch
}

Received 13 March 2014; revised 5 May 2014; accepted 18 May 2014

Copyright (C) 2014 by authors and Scientific Research Publishing Inc.

This work is licensed under the Creative Commons Attribution International License (CC BY). http://creativecommons.org/licenses/by/4.0/

(c) $\underset{\mathrm{EY}}{\mathrm{EY}}$ Open Access

\begin{abstract}
Schools are a key setting for promoting physical activity in children. There is little evidence on the potential of widely implemented programs to improve the quality of physical education (PE). The aim was to assess the effects of a short training course for classroom teachers on the quality of PE, assessed as activity time during PE. A quasi-experimental study was conducted with 6 intervention $(\mathrm{N}=86)$ and 13 control classes $(\mathrm{N}=151)$. Schools were selected in a random procedure $(26.9 \%$ participation). Participation in children was $86.2 \%$ (mean age 7.8 years, $48.9 \%$ girls). Physical activity was assessed objectively using accelerometers. Effect on time spent in sedentary, moderate, vigorous and moderate-to-vigorous (MVPA) activities, steps and counts/minute during PE were analysed using t-tests and mixed linear models. Physical activity time increased significantly in the intervention but not in the control group between baseline and follow-up (relative increase in moderate-to-vigorous physical activity of $\mathbf{1 2 \%}$ in intervention group). Increases were strongest in girls and in children inactive at baseline. In the mixed linear models adjusted for clustering, the effects were significant in girls for vigorous activities, sedentary time and counts/minute, in inactive children for steps. Results indicate that a short training course for classroom teachers can have subtle positive effects on physical activity time during PE. Girls and the most inactive children at baseline profited most from the intervention.
\end{abstract}

\section{Keywords}

Health Promotion, Physical Activity, Physical Education, Teaching 


\section{Introduction}

The beneficial effects of regular physical activity on children's physical and mental health are well recognised [1]. Schools are ideal settings to reach all children and intense school-based physical activity interventions have been shown to be effective in increasing activity levels in children [2] [3]. Physical education (PE) is often an intervention element. Studies focusing specifically on physical activity during PE lessons reported that higher teachers' skills were associated with more activity time during PE [4] [5], indicating a quality improvement of PE. However, there is a lack of evidence for the effectiveness of interventions that have the potential for wide implementation [6].

In Switzerland, the KISS study is an example of a school-based intervention that effectively increased physical activity levels in children [7]. However, the program was complex and demanding and therefore a wide implementation is challenging. On the other hand, the Swiss Youth + Sport $(\mathrm{Y}+\mathrm{S})$ program is an example of a nationally implemented program for physical activity and sport promotion in older children and adolescents. The program exists since the 1970ies, is embedded in the national sports law and has an annual budget of CHF 60 Mio (around $€ 75 \mathrm{Mio}$ ). In Switzerland, a country with 8 million inhabitants, around 12,000 instructors are trained and 100,000 actively involved every year, around 55,000 sport courses and camps are offered and more than half a million children and adolescents participate each year [8]. $\mathrm{Y}+\mathrm{S}$ sport courses and camps can be offered by trained $\mathrm{Y}+\mathrm{S}$ instructors in different settings such schools, sport clubs or youth clubs and therefore reach a variety of different children and youth. To become a $\mathrm{Y}+\mathrm{S}$ instructor, individuals have to complete a 6-day basic training course in a specific sport discipline and to visit additional course modules every two years in order to keep their $\mathrm{Y}+\mathrm{S}$ instructor's license.

As an extension of $\mathrm{Y}+\mathrm{S}$ operating since 2008, $\mathrm{Y}+\mathrm{S}$ Kids targets children aged 5 to 10 years. $\mathrm{Y}+\mathrm{S}$ Kids received an additional budget of CHF 20 Mio (around $€ 25$ Mio) per year. The program is organised in two settings, namely in schools and in sport clubs. The aim of the school setting is to reach all children, in particular the less active ones, by providing one or more additional PE lessons per week in the frame of extracurricular sports. Classroom teachers offering these additional lessons are trained during a two-day course. The aims of $\mathrm{Y}+\mathrm{S}$ Kids are to improve the quality of sports lessons and are mainly based on sport pedagogic approaches. However, one quality criterion for "good" PE and sports lessons is a high activity time [4] and it has been recommended that children spend at least $50 \%$ of their PE time physically active [9] [10].

Y + S Kids has not only the potential to quantitatively increase physical activity through the additional Y + S Kids lessons, but may also improve the quality of the regular three PE lessons per week required by Swiss federal law through the teachers' training course. In most parts of Switzerland, PE in primary school is given by classroom teachers and not specialists, and the two-day training course should improve their PE teaching skills with the result — among others — of more activity time for children. This could be especially important for less active subgroups of children, such as girls [11] [12]. Furthermore, new movement skills obtained during the additional Y + S Kids lesson may also motivate children to be more active in other contexts.

The potential for the nation-wide implementation of $\mathrm{Y}+\mathrm{S}$ Kids is based on the short and feasible intervention (two-day training course for classroom teachers, additional PE lesson for children in the context of extra-curricular sports), the sufficient and long-term funding, and the available organizational structures and processes set up since the 1970ies in the frame of $\mathrm{Y}+\mathrm{S}$. The effectiveness of the program has not yet been evaluated.

The aims of this study were to describe physical activity time during PE lessons in school children aged 7 - 9 years and to assess changes in physical activity time during PE after the classroom teacher had participated in Y + S Kids teachers' training course. A special focus was on potential sex differences and differences between inactive and active children at baseline. Furthermore, the acceptance and satisfaction with the Y + S Kids teachers' training course will be reported.

\section{Methods}

\subsection{Study Design, Recruitment and Participants}

A quasi-experimental study was conducted between April and September 2012 including 6 intervention $(n=86)$ and 13 control classes $(N=151)$. Schools were selected in a random-based multi-step procedure in cooperation with the public administration of the Swiss Canton of Aargau in autumn/winter 2011/12. Within schools, inclusion criteria for teachers and their classes were that participating teachers had not yet participated in a $\mathrm{Y}+\mathrm{S}$ 
Kids teachers' training course, that they taught first, second or third graders and that they were going to keep the same class in the school year 2012/2013. In total, 72 schools were contacted; 31 (43.1\%) did not meet the inclusion criteria (i.e. there were no teachers fulfilling the inclusion criteria). 19 (46.3\%) of the eligible schools declined to participate, 5 (12.2\%) could not be reached and $6(14.6 \%)$ could be reached but did not answer back. If a school was eligible and interested in the study, the head of the school contacted eligible teachers and provided their names to the study team if they wanted to participate. The study team then contacted the teachers directly. Overall, 11 (26.9\%) of the eligible schools participated in the study, two among them providing two classes each, yielding a total of 13 classes. Finally, 6 more classes from 3 additional schools were recruited with a snowball system, totalling 19 classes from 14 schools. Those teachers willing to participate in the intervention arm of the study were allocated to the intervention group, the other teachers to the control group. All teachers were aware that we were interested in the evaluation of the $\mathrm{Y}+\mathrm{S}$ Kids teachers' training course, however they were not aware that we looked specifically at time spent actively during PE lessons.

Intervention and control classes were not in the same schools. The sample size calculation was based on the following assumptions: based on another Swiss study [12], we expected $15 \mathrm{~min}$ (SD $10 \mathrm{~min}$ ) of moderate-tovigorous activity (MVPA) in a PE lesson of $45 \mathrm{~min}$. We assumed that after the intervention MVPA would increase to $18 \mathrm{~min}$. With a power of $\beta=0.8$, a significance level of $\alpha=0.05$ and adjustment for clustering within classes, using an intraclass correlation coefficient of $\rho=0.2$ [13], we expected to be able to show statistically significant intervention effects with about 130 individuals per group.

In each class, parents were informed about the study by a member of the research team during an information event. Written parental consent was obtained for all participating children. The study was approved by the Ethics Committee of the Canton of Aargau, Switzerland. Due to organisational issues, the study could not be blinded; teachers were aware of the group they were in and the group allocation of the classes was known to the assessors. However, teachers were not aware that activity time during PE lessons would be analysed specifically.

\subsection{Assessments}

Baseline assessments took place in April/May 2012, follow-up assessments in September 2012. Physical activity was measured objectively using accelerometers (Actigraph GT3X or GT3X+, Pensacola, FL, USA). The children were asked to wear the devices during 7 consecutive days on the right hip while awake. Detailed instructions were given during a fitness test organised in the frame of this study. An accelerometer was attached to each child's hip by a member of the research team. Children were asked to remove the accelerometers while sleeping and during water-based activities. An epoch time of 5 seconds was chosen in order to account for the short bouts of moderate and vigorous activities usually observed in children [14]. At follow-up, the same accelerometer used at baseline was given to each child.

For the present analyses, physical activity data during regular PE lessons were included while the extra-curricular Y + S Kids course for children was not. Generally, three PE lessons per week are compulsory in Switzerland. However, one lesson per week may be replaced by a swimming lesson (during which children did not wear the accelerometer). The days and time of PE lessons were available from the teachers. Information on whether a child had participated in the lesson was available from a short diary that the parents completed during accelerometer assessments. A child was included if data was available for at least one PE lesson both at baseline and follow-up. On average, 2.1 and 2.4 PE lessons per class took place at baseline and follow-up, respectively. Accelerometer data of the children was available for $91.4 \%$ of lessons at baseline and for $82.8 \%$ at follow-up with no differences between groups, gender and activity level at baseline. The software Actilife 6 was used to extract and process the data. Time spent in sedentary ( 0 - 25 counts/15seconds), light ( 26 - 573 counts/15seconds), moderate (574 - 1002 counts/15seconds) and vigorous ( $\geq 1003$ counts/15seconds) physical activity was calculated based on cut points developed by Evenson et al. [15]. These cut points were chosen as they performed best in a comparison study [16]. In addition, the number of steps and the mean counts per minute were analysed. Most PE lessons were 45 minutes, however a few were longer (mean 46.1 minutes at baseline and 45.2 minutes at follow-up) and therefore the data were standardised to a PE lesson of 45 minutes.

During the fitness test, height and weight were measured and body mass index (BMI) was calculated. Ageand sex-specific cut points were used to define overweight [17]. Parental education and place of birth were as- 
sessed in a parental questionnaire. High education was defined as having a tertiary education such as a university degree. Children were classified as having a migration background if at least one parent was born abroad [18].

\subsection{Intervention}

The intervention was a standardised two-day $\mathrm{Y}+\mathrm{S}$ Kids training course for classroom teachers, which was held on a weekend in June 2012. The aim of the training course was to support classroom teachers to plan and conduct PE lessons that are more age-specific and intense. The focus was practice-oriented, providing participants with a wealth of new didactical material such as model lessons, booklets or music CDs for physical activity and sports in young primary school children. A specific emphasis was given to organisational aspects such as giving children the opportunity to learn and experience different activities during most of the lesson. In addition, teachers had to learn about the specific administrative requirements of the $\mathrm{Y}+\mathrm{S}$ Kids programme. Increasing physical activity time during regular PE was not an explicit goal of the teachers' training course and was thus not communicated to the teachers as such.

A standard course evaluation took place among all course participants $(\mathrm{N}=41$, including the six teachers of the intervention classes) using questionnaires. Course satisfaction and practicability were assessed with fivepoint likert scales; course organization, infrastructure, content and instructors with open-ended questions. In addition, the six teachers of the intervention classes were contacted by telephone in November 2012 to conduct a structured interview with open-ended questions. Teachers were asked about their satisfaction with the course five months later and their experiences in implementing course contents into the Y + S Kids course they offer for their students.

\subsection{Statistical Analyses}

The outcome measures used were time spent in sedentary, moderate, vigorous and MVPA, as well as the total number of steps and the mean counts per minute during PE. Descriptive analyses included means and standard deviations. Unpaired t-tests were used for the comparison between intervention and control group and paired t-tests for the comparison between baseline and follow-up levels within groups in unadjusted descriptive analyses. Two-sided $\mathrm{p}$-values were used and the significance level was set to $\mathrm{p}<0.05$. Regression models adjusting for clustering within classes were used to compare baseline and follow-up values between groups.

Tertiles according to MVPA during PE at baseline were calculated for the intervention and the control group separately in order to perform sub group analyses for the most inactive compared to the most active children.

Mixed linear models adjusted for sex, age, education of parents, child's migrational background and overweight were used to simultaneously analyse the effects of time and group. The reported values are the time $x$ group interaction terms that allow identification of potential differences in changes between groups over time. For each model p values for two versions are presented, one without and one with taking into account clustering within classes (effect estimates remain the same irrespective of taking into account clustering). Analyses were carried out using STATA version 12 (StataCorp LP, College Station, Texas, 2011).

\section{Results}

\subsection{Participants}

The 19 included classes comprised 340 children of which 293 consented to participate (86.2\%). For the present analyses, only children with physical activity data of at least one PE lesson at baseline and follow-up were included ( $\mathrm{N}=237,80.9 \%$ of participating children).

Table 1 presents the characteristics of the included children $(\mathrm{N}=237)$. There were no significant differences between the intervention and the control classes except that a lower proportion of mothers of children in the intervention classes had a high education $(\mathrm{p}=0.02)$.

\subsection{Changes in Physical Activity during PE Lessons}

Table 2 presents the physical activity time during PE lessons at baseline and follow-up separately for the intervention and the control group. At baseline, children in the intervention group spent $27.6 \%$ of their PE time in MVPA, those in the control group $31.8 \%$. After adjustment for clustering within classes, baseline differences 
Table 1. Baseline characteristics of included children.

\begin{tabular}{cccccc}
\hline & & Total & Intervention & Control & $\mathrm{p}$ \\
\hline $\mathrm{N}$ & & 237 & 86 & 151 & \\
Age, mean (SD) & Years & $7.8(0.7)$ & $7.8(0.5)$ & $7.9(0.8)$ & 0.34 \\
Girls, \% & & 48.9 & 51.2 & 47.7 & 0.61 \\
Overweight, \% & & 17.4 & 16.3 & 18.1 & 0.72 \\
Education father, \% & High & 40.5 & 42.7 & 39.1 & 0.60 \\
Education mother, \% & High & 29.7 & 20.5 & 35.3 & 0.02 \\
Migrant background child, \% & Yes & 43.9 & 44.4 & 43.6 & 0.90 \\
\hline
\end{tabular}

Table 2. Physical activity time during PE lessons at baseline and follow-up, by group, by sex.

\begin{tabular}{|c|c|c|c|c|c|c|}
\hline & Baseline & Follow-up & $\mathrm{p}$ & Baseline & Follow-up & $\mathrm{p}$ \\
\hline \multicolumn{7}{|l|}{ Total } \\
\hline & \multicolumn{3}{|c|}{ Intervention group $(\mathrm{n}=86)$} & \multicolumn{3}{|c|}{ Control group $(\mathrm{n}=151)$} \\
\hline Sedentary, mean min (SD) & $15.4(4.9)$ & $13.5(3.4)$ & $<0.001$ & $14.4(4.0)$ & $14.1(3.5)$ & 0.31 \\
\hline Moderate, mean min (SD) & $5.6(1.6)$ & $6.0(1.3)$ & 0.046 & $6.1(1.5)$ & $6.2(1.3)$ & 0.35 \\
\hline Vigorous, mean min (SD) & $6.8(3.0)$ & $7.9(2.8)$ & $<0.001$ & $8.2(2.8)$ & $8.1(2.9)$ & 0.53 \\
\hline MVPA, mean min (SD) & $12.4(4.1)$ & 13.9 (3.3) & $<0.001$ & $14.3(3.5)$ & $14.3(3.4)$ & 0.93 \\
\hline Steps, mean (SD) & $1558(491)$ & 1802 (359) & $<0.001$ & $1880(406)$ & $1793(360)$ & 0.02 \\
\hline counts/min, mean (SD) & 1699 (559) & 1924 (495) & $<0.001$ & $1920(474)$ & 1926 (499) & 0.89 \\
\hline \multicolumn{7}{|l|}{ Boys } \\
\hline & \multicolumn{3}{|c|}{ Intervention group $(n=42)$} & \multicolumn{3}{|c|}{ Control group $(n=79)$} \\
\hline Sedentary, mean min (SD) & $13.4(5.2)$ & $13.1(3.6)$ & 0.75 & $13.3(3.6)$ & $13.2(3.6)$ & 0.79 \\
\hline Moderate, mean min (SD) & $6.3(1.7)$ & $6.2(1.2)$ & 0.67 & $6.7(1.5)$ & $6.5(1.3)$ & 0.43 \\
\hline Vigorous, mean min (SD) & $7.8(3.0)$ & $8.6(2.8)$ & 0.11 & $9.0(2.9)$ & $9.0(2.9)$ & 0.97 \\
\hline MVPA, mean min (SD) & $14.1(4.1)$ & $14.7(3.2)$ & 0.32 & $15.7(3.4)$ & $15.5(3.3)$ & 0.76 \\
\hline Steps, mean (SD) & $1626(551)$ & $1861(360)$ & 0.01 & $2022(416)$ & 1899 (372) & 0.04 \\
\hline counts/min, mean (SD) & $1878(554)$ & 2016 (488) & 0.08 & 2058 (469) & 2078 (510) & 0.75 \\
\hline \multicolumn{7}{|l|}{ Girls } \\
\hline & \multicolumn{3}{|c|}{ Intervention group $(n=44)$} & \multicolumn{3}{|c|}{ Control group $(\mathrm{n}=72)$} \\
\hline Sedentary, mean min (SD) & $17.4(3.6)$ & $13.9(3.3)$ & $<0.001$ & $15.6(4.0)$ & $15.1(2.8)$ & 0.23 \\
\hline Moderate, mean min (SD) & $5.0(1.3)$ & $5.9(1.3)$ & $<0.001$ & $5.5(1.2)$ & $5.9(1.3)$ & 0.03 \\
\hline Vigorous, mean min (SD) & $5.9(2.8)$ & $7.2(2.7)$ & $<0.001$ & $7.4(2.5)$ & $7.0(2.5)$ & 0.30 \\
\hline MVPA, mean min (SD) & $10.9(3.4)$ & $13.1(3.2)$ & $<0.001$ & $12.9(2.9)$ & $13.0(2.9)$ & 0.81 \\
\hline Steps, mean (SD) & 1493 (423) & 1746 (353) & $<0.001$ & 1725 (333) & 1676 (309) & 0.30 \\
\hline counts/min, mean (SD) & $1529(514)$ & $1837(492)$ & $<0.001$ & $1768(434)$ & 1759 (433) & 0.88 \\
\hline
\end{tabular}

between intervention and control group were not significant (all $p \geq 0.22$ ). Girls were significantly less active during PE at baseline than boys according to all variables (all $\mathrm{p} \leq 0.001$, intervention and control group together). Sex differences were still present at follow-up for some variables, however they were less pronounced in the intervention group. 
Overall, there was a relative increase of $12 \%$ in MVPA in the intervention group while there was no change in the control group. Table 2 displays changes between baseline and follow-up in boys and girls. In girls of the intervention group, there was a significant decrease in sedentary and a significant increase in activity time between baseline and follow-up for all variables. In boys, there was only a significant increase in the number of steps. In the control group, the only significant changes were a decrease in steps in boys and an increase in time spent in moderate activities in girls.

Furthermore, children in the lowest tertile according to MVPA during PE at baseline were compared to those in the highest tertile (Table 3). In the intervention group, there was a statistically significant increase in all activity variables in the most inactive third (all $\mathrm{p}<0.001$; e.g. increase in MVPA from 8.0 to 12.5 minutes). In the most active third, there was only a slight but significant decrease in time spent in moderate activities (from 7.0 to 6.4 minutes, $p=0.03$ ). In the control group, there was also a significant increase in all activity variables in the most inactive third (all $\mathrm{p} \leq 0.01$ ), however the changes were smaller than in the intervention group. In the most active third among the controls, there was a significant decrease in activity time for all variables (all $\mathrm{p} \leq 0.001$ ).

Table 4 presents the results of the mixed linear models. When clustering was not taken into account, several differences in changes expressed by the time $\times$ group interaction term coefficients were significant. However, when taking into account clustering, some differences of change ceased to be so. For the whole sample, differences in change between baseline and follow-up in the number of steps remained of borderline significance $(\mathrm{p}=$ 0.056) with a higher positive change in the intervention compared to the control group. In girls, the decrease in sedentary time was significantly higher in the intervention than in the control group, and so was the increase in time spent in vigorous activities and in counts/minute. There were no significant differences in change in boys. In the most inactive third, the increase in steps was significantly higher in the intervention compared to the control group, while the change differences in MVPA were borderline significant $(p=0.058)$. In the most active third, changes in steps were significantly more favourable in the intervention than in the control group.

\subsection{Acceptance of and Satisfaction with the $Y+S$ Kids Teachers' Training Course}

Immediately after the $\mathrm{Y}+\mathrm{S}$ Kids training course, all 41 course participants were satisfied with course content,

Table 3. Physical activity time during PE lessons at baseline and follow-up, by group, by activity at baseline.

\begin{tabular}{|c|c|c|c|c|c|c|}
\hline & Baseline & Follow-up & $\mathrm{p}$ & Baseline & Follow-up & $\mathrm{p}$ \\
\hline \multicolumn{7}{|c|}{ Most inactive third at baseline } \\
\hline & \multicolumn{3}{|c|}{ Intervention group $(\mathrm{n}=86)$} & \multicolumn{3}{|c|}{ Control group $(n=151)$} \\
\hline Sedentary, mean min (SD) & $19.2(3.7)$ & $14.3(2.8)$ & $<0.001$ & $17.6(4.0)$ & $15.1(3.8)$ & $<0.001$ \\
\hline Moderate, mean min (SD) & $4.2(0.9)$ & $5.9(1.2)$ & $<0.001$ & $5.2(1.2)$ & $6.0(1.4)$ & 0.001 \\
\hline Vigorous, mean min (SD) & $3.8(1.1)$ & $6.6(2.1)$ & $<0.001$ & $5.4(1.4)$ & $6.9(2.9)$ & $<0.001$ \\
\hline MVPA, mean min (SD) & $8.0(1.4)$ & $12.5(2.7)$ & $<0.001$ & $10.6(1.7)$ & $12.9(3.5)$ & $<0.001$ \\
\hline Steps, mean (SD) & $1130(281)$ & $1712(332)$ & $<0.001$ & $1524(258)$ & $1684(390)$ & 0.01 \\
\hline counts/min, mean (SD) & $1126(181)$ & $1687(364)$ & $<0.001$ & $1456(264)$ & $1737(498)$ & $<0.001$ \\
\hline \multicolumn{7}{|l|}{ Most active third at baseline } \\
\hline & \multicolumn{3}{|c|}{ Intervention group ( $\mathrm{n}=42$ ) } & \multicolumn{3}{|c|}{ Control group $(\mathrm{n}=79)$} \\
\hline Sedentary, mean min (SD) & $10.6(2.8)$ & $11.7(3.7)$ & 0.15 & $11.8(2.5)$ & $13.5(3.6)$ & $<0.001$ \\
\hline Moderate, mean min (SD) & $7.0(1.4)$ & $6.4(1.1)$ & 0.03 & $7.2(1.5)$ & $6.4(1.2)$ & $<0.001$ \\
\hline Vigorous, mean min (SD) & $10.1(2.2)$ & $9.9(2.9)$ & 0.75 & $11.0(2.3)$ & $9.4(3.1)$ & $<0.001$ \\
\hline MVPA, mean min (SD) & $17.1(2.0)$ & $16.3(3.1)$ & 0.18 & $18.2(2.0)$ & $15.8(3.5)$ & $<0.001$ \\
\hline Steps, mean (SD) & $1967(471)$ & $2002(351)$ & 0.72 & $2236(344)$ & $1871(310)$ & $<0.001$ \\
\hline counts/min, mean (SD) & $2332(360)$ & $2300(502)$ & 0.70 & $2392(370)$ & $2143(555)$ & 0.001 \\
\hline
\end{tabular}


Table 4. Results of the mixed linear models, by sex and activity level at baseline.

\begin{tabular}{|c|c|c|c|c|c|c|c|c|c|c|c|c|c|c|c|}
\hline & \multicolumn{3}{|c|}{ All $(\mathrm{N}=237)$} & \multicolumn{3}{|c|}{ Boys $(\mathrm{N}=121)$} & \multicolumn{3}{|c|}{ Girls $(N=116)$} & \multicolumn{3}{|c|}{$\begin{array}{l}\text { Most inactive third } \\
\qquad(\mathrm{N}=78)\end{array}$} & \multicolumn{3}{|c|}{$\begin{array}{l}\text { Most active third } \\
\qquad(\mathrm{N}=80)\end{array}$} \\
\hline & $\operatorname{coeff}^{\mathrm{a}}$ & $\mathrm{p}^{\mathrm{b}}$ & $\mathrm{p}^{\mathrm{c}}$ & $\operatorname{coeff}^{\mathrm{a}}$ & $\mathrm{p}^{\mathrm{b}}$ & $\mathrm{p}^{\mathrm{c}}$ & $\operatorname{coeff}^{\mathrm{a}}$ & $\mathrm{p}^{\mathrm{b}}$ & $\mathrm{p}^{\mathrm{c}}$ & $\operatorname{coeff}^{\mathrm{a}}$ & $\mathrm{p}^{\mathrm{b}}$ & $\mathrm{p}^{\mathrm{c}}$ & $\operatorname{coeff}^{\mathrm{a}}$ & $\mathrm{p}^{\mathrm{b}}$ & $\mathrm{p}^{\mathrm{c}}$ \\
\hline Sedentary time & -1.62 & 0.005 & 0.22 & -0.29 & 0.75 & 0.87 & -2.82 & $<0.001$ & 0.04 & -2.26 & 0.02 & 0.12 & -0.72 & 0.38 & 0.65 \\
\hline Light activities & 0.01 & 0.98 & 0.99 & -0.75 & 0.20 & 0.45 & 0.70 & 0.16 & 0.40 & 0.15 & 0.86 & 0.91 & -0.96 & 0.12 & 0.28 \\
\hline $\begin{array}{l}\text { Moderate } \\
\text { activities }\end{array}$ & 0.30 & 0.21 & 0.53 & 0.15 & 0.66 & 0.81 & 0.37 & 0.24 & 0.49 & 0.85 & 0.02 & 0.07 & 0.33 & 0.30 & 0.58 \\
\hline $\begin{array}{l}\text { Vigorous } \\
\text { activities }\end{array}$ & 1.31 & 0.001 & 0.08 & 0.89 & 0.16 & 0.36 & 1.75 & 0.001 & 0.03 & 1.26 & 0.055 & 0.12 & 1.36 & 0.05 & 0.08 \\
\hline MVPA & 1.61 & 0.001 & 0.13 & 1.03 & 0.19 & 0.48 & 2.12 & 0.001 & 0.06 & 2.11 & 0.01 & 0.06 & 1.68 & 0.02 & 0.12 \\
\hline Steps & 327.02 & $<0.001$ & 0.056 & 370.90 & 0.001 & 0.09 & 277.13 & 0.001 & 0.11 & 416.56 & $<0.001$ & 0.03 & 388.48 & $<0.001$ & 0.01 \\
\hline counts/min & 230.08 & 0.001 & 0.09 & 144.13 & 0.16 & 0.40 & 310.91 & 0.001 & 0.04 & 277.57 & 0.01 & 0.06 & 218.11 & 0.07 & 0.19 \\
\hline
\end{tabular}

${ }^{\mathrm{a}}$ Coefficient for interaction term "time $\times$ group”. ${ }^{\mathrm{b}} \mathrm{p}$-values for models without taking into account clustering within classes. 'p-values for models taking into account clustering within classes, Note: all models were adjusted for sex, age, education of parents, migration background of child and overweight.

$56 \%$ were even completely satisfied. $93 \%$ reported that they would be able and $7 \%$ that they would be partly able to use what they had learnt in the course in practice. $90 \%$ of course participants were planning to offer a Y + S course. Overall, the general comments on the teachers' training course were positive, with some reservations about the administrational requirements of the program.

The six teachers of the intervention classes still rated their training course very positive five months later. They especially appreciated its practice-orientated format and they reported to frequently use the course material. Again, two of the six intervention teachers still mentioned their reservations about the administrative requirements.

\section{Discussion}

There was a small but statistically significant increase in activity time and a decrease in sedentary time during $\mathrm{PE}$ in the intervention group between baseline and follow-up while there were no significant changes in the control group, indicating that there was an intervention effect of the $\mathrm{Y}+\mathrm{S}$ Kids teachers' training course in regular PE lessons. In particular, girls and the least active children at baseline profited most with highest increases in activity time in the intervention group. These results suggest that also less extensive school-based interventions that are feasible for wide implementation have the potential to improve the quality of PE lessons as indicated by activity time of children. Y + S Kids is already widely implemented in Switzerland and is therefore a good example of a feasible and effective national program. Moreover, the high acceptance of the teachers' training course supports the feasibility of wide implementation.

Even though the PE lessons are the same for boys and girls, girls were less active at baseline than boys. The intervention was able to decrease this gender difference perhaps in the way that activities were performed that are also attractive for girls.

The share of MVPA during PE in our study (27\% in intervention, 31.8\% in control group at baseline) was lower than the average of $37 \%$ derived from other studies included in a review [19], though it has to be noted that the majority of those studies had not used accelerometers to assess physical activity. Shares of $11 \%$ to $13 \%$ [20] or 33\% [12] of MVPA in PE were found in more recent studies when accelerometers were used. In accelerometer studies, activity time also depends on cut points, selecting lower ones increases activity time [21]. The two other studies have used 15\% lower [20] and 13\% lower [12] cut points than our study. Therefore, there is some limitation regarding the comparability of proportions of activity times between studies. In our study, as in the other Swiss investigation, girls were less active than boys. However, such a sex difference had generally not been found in the earlier review [19].

The analyses revealed that the increase in activity time in the intervention group was mainly due to changes in vigorous-intensity activities, as reported elsewhere [11]. These effects were most pronounced in girls. As vigorous-intensity activities account for a relatively low amount of total (MVPA) activity during a general day (around 13\% in girls and 17\% in boys [22]), an increase in such activities during PE is most welcome. However, 
it also has to be noted that even though the changes were statistically significant, they were small (in the range of 1 minute for vigorous-intensity activities and 1.5 minutes in MVPA for one PE lesson or a 12\% increase in activity time from $27.5 \%$ to $30.1 \%$ ), indicating that there is still room for improvement, especially when $50 \%$ of time spent with MVPA during PE is recommended [9] [10].

For the most inactive third at baseline, increases in activity time were also observed in the control group, however these were smaller than in the intervention group. Furthermore, while the most active children in the intervention group maintained activity time, this group of children in the control group significantly decreased theirs. This may be interpreted as "regression to the mean" [23] in the control group, a phenomenon which could not be observed in the intervention group.

The intraclass correlation coefficients were between 0.1 and 0.3 for most outcome variables (data not shown) and therefore in the range assumed when doing the sample size calculations. The fact that several of the associations in the mixed linear models (Table 4) were not significant anymore after taking into account clustering indicates that the teachers had a considerable influence on children's physical activity levels during PE classes.

As the proportion of time spent in physical activity also depends on the cut points as described above, it is theoretically possible that the choice of cut points may also have affected the observed differences in physical activity over time. However, it is unlikely that the effects of different cut points on activity time are differential with respect to intervention and control group and would so alter the net intervention effect.

Other studies have reported positive effects of interventions on physical activity time during PE [24]. All these studies assessed physical activity using the System for Observing Fitness Instruction Time (SOFIT) [24] and only one study used accelerometers in combination with SOFIT [25]. Direct comparability of intervention effects is thus limited. Increases in activity time up to $20 \%$ when comparing intervention to control groups were reported when using observational assessment. In the one study also using accelerometers a significant increase in time spent in MVPA of $14 \%$ in the intervention compared to a $4 \%$ increase in the control group was found when activity time was assessed by observation, however no effects were found according to accelerometer data [25]. Only in two of the studies included, the intervention was based on teaching PE teachers to better manage and organize PE classes [26] [27] corresponding to the intervention approach in our project; in both studies significant increases in physical activity between $5 \%$ and $13 \%$ by observation were reported. Another intervention supporting teachers to improve PE teaching in terms of increasing activity time reported a significant $3.3 \%$ increase in vigorous physical activity and a non-significant 4.5\% increase in MVPA in the intervention compared to the control classes translating to a gain of $<1$ minute of MVPA per average 21-minute lesson [11]. When investigating the influence of the PE teachers' professional background the SPARK study found highest physical activity levels during PE when taught by trained PE specialists, followed by trained classroom teachers and untrained classroom teachers [4]. Overall, the intervention effects in our study were comparable to those reported by others, confirming those findings obtained from studies using observational assessment by objectively assessed changes in physical activity.

The strength of our study is the objective assessment of physical activity, the high participation rate at the level of children, the standardised intervention for all teachers of the intervention class, and the investigation of a widely implemented intervention. The study design (quasi-experimental rather than randomised) may be regarded as a limitation, however it was not feasible to randomly assign participating teachers to the intervention which also included offering an additional PE lesson ( $Y+S$ Kids course) for their class during one year. The follow-up was relatively short, but we assumed that effects on the quality of PE should be observable soon after the intervention. Due to organisational issues, the study could not be blinded. The participation rate at the school level (26.9\%) may seem low; however, the main reasons for non-participation were other priorities of the schools and not a general lack of interest. A similar selection mechanism regarding participation in the $\mathrm{Y}+\mathrm{S}$ Kids program is likely to also take place outside this study. Therefore, the results of our study should be generalisable to teachers and classes participating in Y + S Kids not in the context of this study. We could only reach about $90 \%$ of the target sample size of 260 children; moreover, the group allocation was unbalanced (86 in intervention group, 151 in control group). This may be a reason why the mixed linear models reached significance only in some sub groups and for specific physical activity variables.

Ideally, further research should include a randomised study design, assess also other quality indicators of PE, look at changes in overall physical activity in a larger sample and also integrate long-term maintenance of physical activity. Whether a specific focus of training courses aiming at an increase in activity time during PE would bring further improvements in physical activity remains to be explored. 


\section{Conclusion}

In conclusion, this study indicates that a short two-day teachers' training course for classroom teachers aiming at increasing didactical and organisational skills in the context of a nation-wide available physical activity and sport program can have subtle positive effects on quality of PE assessed as physical activity time during PE classes, particularly in girls and the least active children. Even though the absolute increase in the range of 1.5 minutes in all intervention children and 4.5 minutes in those inactive at baseline is quite small, it is in line with results reported in other studies [11] [27]. This is the first study on the effectiveness of the widely implemented $\mathrm{Y}+\mathrm{S}$ Kids program regarding a quality improvement of PE assessed as activity time during PE.

\section{Acknowledgements}

This study was funded by the Swiss Research Concept Sports and Physical Activity 2008-2011 (grant 11-05), the Swiss Council for Accident Prevention, Migros culture percentage, the Swiss Foundation for the Health of Children and Adolescents, and the Swiss Association of Sports Medicine.

We thank Martin Jeker, former head of the Y + S program for early input concerning the intervention hypothesis; Christian Koch and Christian Müller, Canton of Aargau, for their support regarding recruitment and for the organization of the teachers’ training course; Nadine Eberle, Sabrina Eibisch, Michèle Geissbühler, Theo Härry, Pascal Hostettler, Melanie Keller, Mirco Trachsel and Claudia Wintersohle for their assistance in the data collection; Burkhardt Seifert for statistical advice. And we thank all teachers, headmasters, children and parents for their participation in the study.

\section{Funding}

This study was funded by the Swiss Research Concept Sports and Physical Activity 2008-2011 (grant 11-05), the Swiss Council for Accident Prevention, Migros culture percentage, the Swiss Foundation for the Health of Children and Adolescents, and the Swiss Association of Sports Medicine.

\section{References}

[1] Physical Activity Guidelines Advisory Committee (2008) Physical Activity Guidelines Advisory Committee Report 2008. US Department of Health and Human Services, Washington DC.

[2] Kriemler, S., Meyer, U., Martin, E., van Sluijs, E.M., Andersen, L.B. and Martin, B.W. (2011) Effect of School-Based Interventions on Physical Activity and Fitness in Children and Adolescents: A Review of Reviews and Systematic Update. British Journal of Sports Medicine, 45, 923-930. http://dx.doi.org/10.1136/bjsports-2011-090186

[3] van Sluijs, E.M., McMinn, A.M. and Griffin, S.J. (2007) Effectiveness of Interventions to Promote Physical Activity in Children and Adolescents: Systematic Review of Controlled Trials. BMJ, 335, 703. http://dx.doi.org/10.1136/bmj.39320.843947.BE

[4] Sallis, J.F., McKenzie, T.L., Alcaraz, J.E., Kolody, B., Faucette, N. and Hovell, M.F. (1997) The Effects of a 2-Year Physical Education Program (SPARK) on Physical Activity and Fitness in Elementary School Students. Sports, Play and Active Recreation for Kids. American Journal of Public Health, 87, 1328-1334. http://dx.doi.org/10.2105/AJPH.87.8.1328

[5] McKenzie, T.L., Sallis, J.F., Faucette, N., Roby, J.J. and Kolody, B. (1993) Effects of a Curriculum and Inservice Program on the Quantity and Quality of Elementary Physical Education Classes. Research Quarterly for Exercise \& Sport, 64, 178-187. http://dx.doi.org/10.1080/02701367.1993.10608795

[6] van Sluijs, E.M. and McMinn, A. (2010) Preventing Obesity in Primary Schoolchildren. BMJ, 340, c819. http://dx.doi.org/10.1136/bmj.c819

[7] Kriemler, S., Zahner, L., Schindler, C., Meyer, U., Hartmann, T., Hebestreit, H., Brunner-La Rocca, H.P., van Mechelen, W. and Puder, J.J. (2010) Effect of School Based Physical Activity Programme (KISS) on Fitness and Adiposity in Primary Schoolchildren: Cluster Randomised Controlled Trial. BMJ, 340, c785. http://dx.doi.org/10.1136/bmj.c785

[8] Kelly, P., Cavill, N. and Foster, C. (2009) An Analysis of National Approaches to Promoting Physical Activity and Sports in Children and Adolescents. Edited by British Heart Foundation Health Promotion Research Group University of Oxford. Oxford, WHO, 33-34.

[9] Association for Physical Education (2008) Physical Education's Contribution to Public Health. afPE Summary Position Paper. Physical Education Matters, 3, 8.

[10] National Center for Health Statistics (2012) Healthy People 2010. Final Review. Hyattsville, MD, 22-28. 
[11] van Beurden, E., Barnett, L.M., Zask, A., Dietrich, U.C., Brooks, L.O. and Beard, J. (2003) Can We Skill and Activate Children through Primary School Physical Education Lessons? "Move It Groove It”-A Collaborative Health Promotion Intervention. Preventive Medicine, 36, 493-501. http://dx.doi.org/10.1016/S0091-7435(02)00044-0

[12] Meyer, U., Roth, R., Zahner, L., Gerber, M., Puder, J.J., Hebestreit, H. and Kriemler, S. (2011) Contribution of Physical Education to Overall Physical Activity. Scandinavian Journal of Medicine \& Science in Sports, 23, 600-606.

[13] Twisk, J.W.R. (2006) Sample-Size Calculations in Multilevel Studies. In: Applied Multilevel Analysis, Cambridge University Press, Cambridge, 127. http://dx.doi.org/10.1017/CBO9780511610806.009

[14] Bailey, R.C., Olson, J., Pepper, S.L., Porszasz, J., Barstow, T.J. and Cooper, D.M. (1995) The Level and Tempo of Children's Physical Activities: An Observational Study. Medicine \& Science in Sports \& Exercise, 27, 1033-1041. http://dx.doi.org/10.1249/00005768-199507000-00012

[15] Evenson, K.R., Catellier, D.J., Gill, K., Ondrak, K.S. and McMurray, R.G. (2008) Calibration of Two Objective Measures of Physical Activity for Children. Journal of Sports Sciences, 26, 1557-1565. http://dx.doi.org/10.1080/02640410802334196

[16] Trost, S.G., Loprinzi, P.D., Moore, R. and Pfeiffer, K.A. (2011) Comparison of Accelerometer Cut Points for Predicting Activity Intensity in Youth. Medicine \& Science in Sports \& Exercise, 43, 1360-1368. http://dx.doi.org/10.1249/MSS.0b013e318206476e

[17] de Onis, M., Onyango, A.W., Borghi, E., Siyam, A., Nishida, C. and Siekmann, J. (2007) Development of a WHO Growth Reference for School-Aged Children and Adolescents. Bulletin of the World Health Organization, 85, 660667. http://dx.doi.org/10.2471/BLT.07.043497

[18] Federal Statistical Office (FSO) (2002) Ein Drittel der Schweizer Bevölkerung sind Migranten oder Nachkommen von Migranten (One Third of the Swiss Population Are Migrants or Offspring of Migrants). Neuenburg.

[19] Fairclough, S.J. and Stratton, G. (2006) A Review of Physical Activity Levels during Elementary School Physical Education. Journal of Teaching in Physical Education, 25, 239-257.

[20] Nettlefold, L., McKay, H.A., Warburton, D.E., McGuire, K.A., Bredin, S.S. and Naylor, P.J. (2011) The Challenge of Low Physical Activity during the School Day: At Recess, Lunch and in Physical Education. British Journal of Sports Medicine, 45, 813-819. http://dx.doi.org/10.1136/bjsm.2009.068072

[21] Loprinzi, P.D., Lee, H., Cardinal, B.J., Crespo, C.J., Andersen, R.E. and Smit, E. (2012) The Relationship of Actigraph Accelerometer Cut-Points for Estimating Physical Activity with Selected Health Outcomes: Results from NHANES 2003-06. Research Quarterly for Exercise \& Sport, 83, 422-430.

[22] Troiano, R.P., Berrigan, D., Dodd, K.W., Masse, L.C., Tilert, T. and McDowell, M. (2008) Physical Activity in the United States Measured by Accelerometer. Medicine \& Science in Sports \& Exercise, 40, 181-188. http://dx.doi.org/10.1249/mss.0b013e31815a51b3

[23] Shephard, R.J. (2003) Regression to the Mean. A Threat to Exercise Science? Sports Medicine, 33, 575-584. http://dx.doi.org/10.2165/00007256-200333080-00003

[24] Slingerland, M. and Borghouts, L. (2011) Direct and Indirect Influence of Physical Education-Based Interventions on Physical Activity: A Review. Journal of Physical Activity and Health, 8, 866-878.

[25] Verstraete, S.J.M., Cardon, G.M., De Clercq, D.L.R. and De Bourdeaudhuij, I.M.M. (2007) Effectiveness of a TwoYear Health-Related Physical Education Intervention in Elementary Schools. Journal of Teaching in Physical Education, 26, 20-34.

[26] Fairclough, S. and Stratton, G. (2005) Improving Health-Enhancing Physical Activity in Girls' Physical Education. Health Education Research, 20, 448-457. http://dx.doi.org/10.1093/her/cyg137

[27] McKenzie, T.L., Nader, P.R., Strikmiller, P.K., Yang, M., Stone, E.J., Perry, C.L., Taylor, W.C., Epping, J.N., Feldman, H.A., Luepker, R.V., et al. (1996) School Physical Education: Effect of the Child and Adolescent Trial for Cardiovascular Health. Preventive Medicine, 25, 423-431. http://dx.doi.org/10.1006/pmed.1996.0074 